\title{
Nuevos interrogantes en el modelo de provisión de cuidados en Andalucía ${ }^{1}$
}

\author{
Inmaculada Zambrano Álvarez \\ Universidad Pablo de Olavide de Sevilla \\ <izamalv@upo.es>
}

María Teresa Martín Palomo

Universidad Carlos III de Madrid

\section{José María Muñoz Terrón}

Universidad de Almería

\section{Evangelina Olid González \\ Universidad de Sevilla}

Artikulu honetan gogoeta egiten da Andaluzian buruturiko 'Zainketa-lanen geografiak. Enplegua sortzeko pribatizazioaren eraginak' azterlanaren inguruan. Bertan burutzen da mendetasun egoeran dauden pertsonen arretaren inguruko antolaketa sozialaren eta kudeaketa publikoaren inguruko analisi bat, eta beronen xedea da zainketak eskaintzeko egituraren mapa baten profila egitea, oinarri hartuz bertan inplikatuta dauden eragile desberdinen rolen azterketa. Halaber, ebaluatzen dira Norberaren Autonomia Sustatzeko eta Mendetasunaren Arretarako Legea ezarri zenetik nabarmenduriko aldaketak. Bertan azaltzen da krisialdi ekonomikoak eta politika zorroztaileek sakonean eragin diola legearen zutabe nagusienetakoa den izaera unibertsalerako bokazioari.

\section{GAKO-HITZAK:}

Zainketak, politika publikoak, generoa, krisialdia.
Este artículo presenta una reflexión del estudio realizado en Andalucía como parte del proyecto 'Geografías del trabajo de cuidados. Implicaciones de su privatización para la creación de empleo'. Se aborda un análisis de la organización social del cuidado y la gestión pública de la atención a las personas en situación de dependencia, con el fin de perfilar un mapa de la estructura de la provisión del cuidado, a partir del papel desempeñado por los diferentes actores implicados. Además, se evalúan los cambios experimentados a partir de la implantación de la Ley de Promoción de la Autonomía Personal y Atención a las Personas en Situación de Dependencia (LAPAD). Se pone de manifiesto cómo la crisis económica y las políticas de austeridad remueven, profundamente, uno de los pilares de dicha ley: su vocación de universalidad.

\section{Palabras Clave:}

Cuidados, políticas públicas, género, crisis.

${ }^{1}$ Este trabajo ha sido financiado por el Ministerio de Economía y Competitividad (Proyecto 'Geografías del trabajo de cuidados. Implicaciones de su privatización para la creación de empleo’, Plan Nacional de I+D+i, referencia CSO2012-32901). Una primera versión, presentada en el V Congreso de la Red Española de Política Social (REPS), “Desigualdad y democracia: políticas públicas e innovación social” (Barcelona, 5 y 6 de febrero de 2015), con el título “'Sólo lo más urgente’: de lo universal a lo asistencial en el modelo de atención pública a la dependencia en Andalucía”, está publicada en las actas de dicho congreso. 


\section{Introducción ${ }^{2}$}

En este artículo se presenta una reflexión en torno a los resultados de un estudio realizado en Andalucía, como parte del proyecto 'Geografías del trabajo de cuidados. Implicaciones de su privatización para la creación de empleo’3, que aborda una comparación entre las comunidades autónomas de Andalucía, Madrid, Galicia y Navarra, en cuanto a la organización social de los cuidados. La investigación profundiza en el vínculo entre los fenómenos demográficos, políticos, sociales y económicos más relevantes sobre los que han actuado las políticas públicas desde el comienzo del siglo XXI: el envejecimiento de la población, el cuidado de las personas en situación de dependencia, los procesos migratorios, y la incorporación de las mujeres al mercado laboral. Se evalúan, además, los cambios experimentados en estos ámbitos a partir de la implantación de la Ley de Promoción de la Autonomía Personal y Atención a las Personas en Situación de Dependencia (a la que en adelante se mencionará como “la LAPAD”, o “la Ley”).

Tomando como base el estudio cualitativo realizado en Andalucía, se argumenta que tanto el impacto de la crisis económica, desencadenada a partir de 2007 , como la implantación de la LAPAD en el contexto de dicha crisis, han puesto en cuestión uno de los pilares que sustentaban la Ley en su origen, esto es, la noción de universalidad. En la comunidad autónoma andaluza se ponen de manifiesto con contundencia las tensiones entre los intentos de mantener el Estado de bienestar) y el impacto de las políticas de ajuste de los recursos económicos destinados a las políticas sociales: el sector de la provisión de cuidado se muestra, en este sentido, como un analizador estratégico de dichas dinámicas.

\section{Estado de bienestar, mujeres y atención a las situaciones de "dependencia"}

El bienestar de las personas se alcanza a partir de un complejo ensamblaje de recursos, económicos unos, por lo general conseguidos a través del mercado, vinculados otros con las prestaciones de los sistemas de protección social, y también, a través de lo que aportan las propias familias. Por ello, a la hora de analizar el bienestar social, no se puede disociar el Estado, que puede llegar a adquirir un gran protagonismo en la garantía de dicho bienestar, del mercado y las familias (Sojo, 2007: 157). Como tampoco se puede obviar que, en lo que toca a los recursos públicos, estos siempre son escasos y que la forma que adopta en cada momento y lugar la atención a las necesidades de cuidado de los diferentes miembros de la sociedad, así como la definición de estas necesidades mismas,

${ }^{2}$ Agradecemos las preguntas y sugerencias de los participantes en el panel sobre dependencia del V Congreso de la Red Española de Política Social (REPS); y a sus coordinadoras, la invitación a presentar nuestro trabajo en ese espacio.

${ }_{3}^{3}$ Plan Nacional de I+D+i (ref.: CSO2012-32901), 2013-2016. está condicionada por numerosas decisiones de carácter político que se toman a distinta escala (estatal, autonómica, local). Igualmente cabe recordar que las formas de conceptualizar qué se entiende por cuidado o por dependencia orientan dichas decisiones, por lo que bien puede afirmarse que son nociones que se construyen de forma interrelacionada (Artiaga, 2015).

Tradicionalmente, las familias han asumido el cuidado de sus miembros sobre la base de un reparto por el que han recaído en las mujeres los trabajos relacionados con la vida doméstica, mientras que los hombres han sido los principales responsables del ámbito público. En esta división del trabajo, la familia ocupaba el lugar central como proveedora de protección y seguridad, pero en las últimas décadas este esquema se ha alterado profundamente por la conjunción de determinados cambios sociales (incorporación masiva y constante de las mujeres al mercado laboral, redistribución de tareas y responsabilidades entre los miembros de la familia), demográficos (envejecimiento de la población, tasas de natalidad que no permiten el reemplazo generacional, incremento de la inmigración), políticos (cambios en las atribuciones del Estado, relevancia de las actuaciones a nivel local en el campo de lo social, mercantilización de servicios) y culturales (secularización, individualización, mayor autonomía para las mujeres), entre otros (Martín Palomo, 2008). Aquel modelo ya no es sostenible, lo que nos enfrenta al desafío de pensar cómo se va a cuidar en el futuro, cómo se va a organizar la provisión de cuidado, sobre todo, el de quienes tienen o previsiblemente tendrán, una inexcusable necesidad de él (las personas más pequeñas, y las más mayores, las más enfermas o las menos hábiles para cuidar de sí mismas). Hay formas diversas de dar cobertura a dichas necesidades, sea a través de la familia, de las instituciones públicas, del mercado, sea a través de la sociedad civil, cuatro planos sobre los que puede reposar la organización social del cuidado, en lo que se ha dado en llamar el "diamante del cuidado" (Razavi, 2007), una figura que presentaría cada una de las cuatro caras (familia, Estado, mercado y sociedad civil) con tamaños diferentes según cada sociedad y cuyos contornos pretendemos conocer en Andalucía. En varios trabajos anteriores se ha dado cuenta de los aportes de las familias en este sentido (Martín Palomo, 2010a, 2013, 2014; Langa et al., 2009; Fernández Cordón y Tobío, 2007). En este artículo se profundiza en la perspectiva de otros actores sociales implicados en la provisión de cuidado: mercado, administración pública y organizaciones sociales.

Los desarrollos de políticas en torno al cuidado conforman algunos de los aspectos más interesantes en la política social en este momento y, además, el tratamiento del cuidado se revela como clave para comprender cómo el Estado de bienestar se ha desplegado hasta fechas recientes (Daly y Lewis, 2000), en las que más bien se inicia su repliegue, tal como se han transformado las prioridades políticas 
en la última década para hacer frente a la crisis o para reducir el déficit. Una de las formulaciones con más éxito, y que más debates ha suscitado, es la de Gösta Esping-Andersen (1990), que diferencia tres modelos de Estado de bienestar: socialdemócrata, conservador corporativo y liberal de mercado. Cada uno de estos modelos desarrolla, a su vez, diferentes tipos de política sobre las familias. Esta propuesta ha recibido dos tipos de críticas: una, que hay países, como los mediterráneos, que no encajan en este esquema, y otra, que esta modelización obvia el trabajo no monetizado que realizan las mujeres en las familias y el efecto diferencial de las políticas sobre las mujeres y los hombres (Borchorst, 1994; Lewis, 1992). Este otro modelo, denominado familista, sería incorporado posteriormente por Esping-Andersen, reconociendo la importante aportación de las mujeres al mantenimiento de los respectivos Estados de bienestar.

En las últimas décadas, los debates se orientan hacia el análisis del cuidado de las personas en situación de dependencia, los hijos menores, pero, sobre todo, las personas de edad avanzada (Martín Palomo, 2014). Para estas, las proyecciones de población apuntan a que la demanda de cuidado se incrementará enormemente en los próximos años, a la par que, cada vez habrá menos mujeres disponibles en las familias para hacerse cargo (Tobío et al., 2010). Jane Lewis reivindica que las carencias del Estado de bienestar en relación con las mujeres deben subsanarse de forma inmediata ampliando la dotación de servicios de atención a la vida diaria (Lewis, 1998). Medidas que, tal como señala Teresa Torns, son fundamentales para lograr la equidad de género, siempre que tengan un carácter universal y formen parte de los derechos de ciudadanía (Torns, 2005). Además, se debe encontrar la forma de generar derechos sociales para las mujeres cuidadoras de sus familiares (Saraceno, 2004; Martín Palomo, 2008). Todos estos aspectos en gran medida podrían haber tenido mayor protagonismo en el desarrollo de la LAPAD, con lo que dicha ley bien habría podido generar mecanismos de impulso de la igualdad de género. Pero, como se verá más adelante, esta promesa inicial se ha tornado en una suerte de amargo recuerdo de la declaración de intenciones.

A finales de los años noventa, se comienza a defender la utilización de un nuevo marco analítico para definir a los regímenes de bienestar que incluye las estrategias familiares en la provisión de cuidado, las relaciones existentes entre Estado y familias, y los elementos de subordinación y dependencia entre unos y otros. Efectivamente, los estudios comparativos de la política social empiezan a poner en su centro el cuidado; de hecho, esta es la actividad principal a la que se dirigen los servicios sociales actuales y de cuya cobertura depende en gran medida el avance en la autonomía de las mujeres y la calidad de vida de los más mayores (Martín Palomo, 2014). Tal como señala Martínez Buján (2014), tomando en cuenta algunos de estos elementos, las clasificaciones de los Estados en regímenes de bienestar han abierto la puerta al desarrollo de las tipologías de los regímenes de cuidado (Williams y Gavanas, 2008). Entre estos, el modelo denominado del social care propone una visión multidimensional del cuidado, en el que se incluyen todas las actividades y relaciones involucradas en el sostenimiento de las necesidades físicas y emocionales de las personas menores y adultas que necesitan cuidado, así como los marcos normativos, económicos y sociales en los que se desarrollan (Daly y Lewis, 2000). El interés de este modelo reside en que implica dos niveles de análisis (un nivel macro, el de las políticas, y un nivel micro, el de las prácticas cotidianas), para preguntar cómo se reparte el cuidado entre Estado, familia, mercado y sociedad civil, y dentro de la familia entre géneros y entre generaciones (Letablier, 2007). En este sentido, las políticas públicas afrontan el desafío de dar una respuesta equitativa a estas situaciones diferenciales en que se encuentran las familias (Martín Palomo, 2009), o bien compensarlas en la medida de lo posible, fomentando la solidaridad entre las generaciones y la equidad de género (Nussbaum, 2002).

El modelo del social care permite pensar, pues, en una reordenación de las obligaciones y los derechos de cada actor: familias, instituciones y agencias privadas. Este modelo es sugerente en la medida en que amplía el campo social del cuidado: de la familia y el espacio definido como privado -doméstico- pasa a un entorno social mucho más vasto. Un esquema que implica revisar tanto las forzadas dicotomías de la modernidad, como la borrosa frontera entre lo público y lo privado, o la que se establece entre autonomía y dependencia, lo que implica también repensar los marcos teóricos sobre los que se construyen estas nociones (Martín Palomo, 2010b; Martín Palomo y Muñoz Terrón, 2015).

En un amplio abanico de propuestas, se reclama que el Estado asuma ciertas responsabilidades que le corresponden e intervenga en beneficio de quienes tienen necesidades específicas, distribuyendo las cargas de tal modo que se promueva la justicia social, lo que conlleva una adecuada dotación de medios y programas para atender a las situaciones y agentes de especial vulnerabilidad (Kittay, 2002; McLaughin, 2003). Es decir, responder a las necesidades de quienes requieren cuidado deviene una responsabilidad colectiva de la sociedad y una responsabilidad moral de las personas. Sobre esta base, se puede impulsar la corresponsabilidad, como solución de nivel micro, en las relaciones interpersonales de la vida cotidiana, y la socialización del cuidado, como solución de nivel macro, desde la esfera política (Saraceno, 2004; Tronto, 2005). No obstante, es necesario demostrar cómo funcionará el cuidado más allá de las relaciones personales, de las relaciones familiares, en la esfera pública, es decir, dar respuesta a la cuestión de hasta qué punto el cuidado es institucionalizable (Pattaroni, 2005).

Que sociedad y Estado compartan la atención a las necesidades humanas y los derechos más básicos de las personas, como la salud, la familia, 
el bienestar y los servicios sociales necesarios, ha sido defendido por Naciones Unidas, la Unión Europea y un gran abanico de autores, desde una perspectiva de derechos fundamentales, según la cual la solidaridad está ligada a la justicia, no sólo en los derechos individuales, sino también en los deberes y obligaciones sociales ante las demandas de cuidado (Zambrano, 2004). Pero, como se verá más adelante, aún queda mucho camino por recorrer para que el cuidado sea considerado realmente un derecho social para toda la ciudadanía. No obstante, sólo en la medida en que se incluya como derecho propio y universal de las personas a cuidar y ser cuidadas, se logrará un importante avance, tanto en términos de reconocimiento de lo que hasta hoy está invisibilizado, como en términos de calidad de vida ciudadana, tal como sostiene Laura Pautassi (2007).

En Andalucía se están manteniendo las primeras reuniones para diseñar y poner en marcha un Plan para la Atención a la Dependencia en Andalucía ${ }^{4}$, por lo que se hace aún más urgente, si cabe, avanzar en el conocimiento de la forma que adopta el régimen de cuidado andaluz, en caso de que se pudiera identificar un tal régimen de cuidado, y el grado de uniformidad o heterogeneidad que presenta en los niveles provincial y local.

\section{Objetivos y metodología}

La investigación analiza para la comunidad autónoma andaluza el desarrollo de los siguientes procesos:

a. Cómo se produce la articulación entre las principales agencias de provisión de bienestar y qué papel están jugando cada una para afrontar la crisis.

b. Cómo está segmentado el sector privado de asistencia y cuidado de las personas, qué forma adquiere en la actualidad.

c. Identificar y analizar las distintas modalidades de colaboración entre mercado y administraciones públicas, entre mercado y familia, así como la imbricación del binomio administraciones públicas-mercado con las familias y con el tejido social en la provisión de cuidado.

Para ello, se ha llevado a cabo una aproximación cualitativa mediante entrevistas abiertas realizadas a quince profesionales de la gestión local y autonómica del ámbito de la política social y de la implementación de la LAPAD, a profesionales del sector privado del cuidado, así como a miembros de sindicatos, asociaciones y otros colectivos de la sociedad civil. Si bien el estudio también incluye en su diseño otro tipo de perfiles (por ejemplo, trabajadores del cuidado remunerado en hogares y en centros), las entrevistas que se han analizado para este artículo se enmarcan en tres ejes: profesionales

${ }_{4}^{4}$ Durante 2014, dos miembros del equipo investigador han participado en algunas de estas reuniones. de la gestión pública de la protección social5; gestores de centros de atención a personas mayores en situación de dependencia ${ }^{6}$; y representantes del movimiento asociativo y reivindicativo ${ }^{7}$.

\section{4. "Sólo lo más urgente": un derecho universal no asentado}

Frente al gran impulso inicial que recibió la aplicación de la LAPAD en Andalucía, ha habido diferentes elementos que han frenado o modificado las bases de que partió. Así, dos procesos han intervenido en cómo se ha implantado dicha ley: por un lado, desde el principio se vislumbraron numerosas dificultades por la complejidad que introduce en su gestión el hecho de que estuvieran implicadas diversas administraciones, con trayectorias y culturas organizativas igualmente diferentes entre sí, lo que en un territorio tan extenso como el andaluz no deja de presentar problemas; por otro lado, el hecho de que la ley se aplica precisamente en un momento en que se desencadena una de las crisis económicas, sociales y políticas más virulentas que ha conocido España desde la Guerra Civil. Estas son dos fuertes cortapisas que, junto con las tensiones con la administración central del Estado, de color político diferente al Gobierno autonómico, y las políticas de austeridad impulsadas por la Unión Europea han frenado, reorientado, replanteado la aplicación de la Ley en la comunidad autónoma andaluza.

\subsection{Un proceso burocratizado}

La implantación del Sistema de Atención a la Dependencia en Andalucía (en adelante, SADA) ha ralentizado -en opinión de algunas personas entrevistadas - el acceso efectivo a las prestaciones, así como el reconocimiento del derecho a ciertos servicios como derechos subjetivos, lo que tenía un importante peso teórico en la declaración de motivos de la Ley (Trabajadora Social Ayuntamiento, E3, por ejemplo). En general, este proceso con unos pasos

${ }^{5}$ Gerencia de la Agencia de Servicios Sociales y Dependencia de la Junta de Andalucía (en adelante, Gerencia de la ASSD, E4); Gerencia de la Teleasistencia de la Junta Andalucía (en adelante, Gerencia de la Teleasistencia, E6); Trabajadora Social de la Oficina de Atención a la Dependencia (en adelante, Trabajadora Social OAD, E10); Trabajadora Social Dependencia, Sevilla (en adelante, Trabajadora Social Dependencia, E2); Trabajadora Social Ayuntamiento de Sevilla (en adelante, Trabajadora Social Ayuntamiento, E3); Trabajadora Social Centro de Salud de Granada (en adelante, Trabajadora Social CS, E11).

${ }^{6}$ Director Residencia Privada de un municipio de Granada (en adelante, Director Residencia Privada, E15); Trabajadora Social Residencia Privada de un municipio de Granada (en adelante, Trabajadora Social Residencia Privada, E7); Jefe de Servicio de Empresa Ayuda a Domicilio, Sevilla (en adelante, Gestor Empresa Ayuda a Domicilio, E8); Coordinadora de Servicios Sociales de Empresa Ayuda a Domicilio de Sevilla (en adelante, Coordinadora Empresa Servicio de Ayuda a Domicilio, E9); Directora Residencia Pública de Jaén (en adelante, Directora Residencia Pública, E12); Director de Centro de Día Privado de Almería (en adelante, Director Centro de Día Privado, E14).

Abogada de la Oficina Derechos Sociales de Sevilla (en adelante, Abogada ODS, E1); Delegada Sindical de CC.0O. de Sevilla (en adelante, Delegada Sindical, E13); Miembro de la Asociación Empleadas de Hogar. Sevilla (en adelante, Asociación Empleadas Hogar, E5). 
muy rígidamente marcados tiende a ser considerado como un lastre que arrastra la aplicación de la LAPAD, en todas las entrevistas realizadas. No obstante, en la Agencia de Servicios Sociales y Dependencia (en adelante, ASSD), la empresa pública creada a fines de 2011 que se encarga de la gestión de una parte importante de las políticas en materia de servicios sociales, se insiste en que el objetivo de estos cambios no es otro que el de agilizar todo el procedimiento y la contratación de servicios. Es significativo que la propia denominación de esta Agencia de forma metonímica sintetice en una palabra, "dependencia”, lo que en la ley tiene un significado mucho más amplio. Tal como apuntan Mario Toboso et al. (2010), en su aplicación la LAPAD perdió la promoción de la autonomía personal y en ello Andalucía no presenta ninguna originalidad.

\subsubsection{Una gestión disputada y lenta}

Desde la implantación de la Ley, uno de los principales problemas ha sido el largo tiempo que transcurre desde que una persona inicia los trámites para solicitar atención a su necesidad específica de cuidado, lo que entre usuarios y personal técnico implicado en dicho procedimiento suele denominarse "solicitar la dependencia" (Trabajadora Social Dependencia, E2; Trabajadora Social Ayuntamiento, E3; Trabajadora Social OAD, E3 Trabajadora Social OAD, E10; Trabajadora Social CS, E11), hasta que se llega a un Plan Individualizado de Atención (en adelante, PIA). Esta forma de denominar la demanda a las instituciones públicas, de respuesta a ciertas necesidades concretas de cuidado, es elocuente respecto de uno de los elementos que introduce la Ley: antes de poder obtener el reconocimiento del derecho a un recurso o una ayuda, la persona tiene que ser calificada con un determinado grado de dependencia que se establece en función de unos estándares fijos y, en principio, homogéneos para toda la población. Es sólo esta clasificación, la "concesión de la dependencia", la que abre la puerta de acceso a los servicios y recursos públicos de atención a las necesidades de cuidado. Cargada de una nueva semántica, que los profesionales de los diferentes ámbitos involucrados tienen que conocer para poder participar en ese proceso clasificador, y asumen de forma acrítica, lo que da cuenta de hasta qué punto se ha "naturalizado" su uso en el breve tiempo que lleva implantada la LAPAD. En la resolución de reconocimiento de la dependencia, que lleva a cabo la Junta de Andalucía, se asigna a la persona un determinado grado y nivel de dependencia, al que le corresponde la posibilidad de acceder a una cierta "cartera" de recursos, en función de la cual los trabajadores sociales, de mutuo acuerdo con la persona que solicita la ayuda y sus familiares, elaboran un PIA, en el que deciden qué tipo de servicio se le adjudica o su frecuencia, es decir, la modalidad de cuidado concreta que la persona va a recibir.

El subsiguiente enlentecimiento del proceso se atribuye en algunas entrevistas, al empeño de "la
Junta de Andalucía”, por querer estar presente en el procedimiento y liderarlo, cuando ya existían estructuras y profesionales cualificados en la red de servicios sociales comunitarios, fuertemente enraizados a nivel local, que bien podrían haberse encargado de ello con una adecuada reorganización de recursos y funciones. Y, tal vez, también con nuevas etiquetas y algunas disputas.

Era la oportunidad perfecta para, por fin, desarrollar los servicios sociales comunitarios que llevan tratando con los dependientes desde hace años, que desde los años ochenta no se han tocado. Además, estaba el servicio de ayuda a domicilio que ya estaba creado, lo que pasa es que, a nivel político, era muy jugoso para la Junta estar en el proceso. Se podrían haber fortalecido los servicios sociales comunitarios. La gestión de residencias, ¿quién conoce mejor las residencias que hay en su zona, los centros de día, los recursos que las trabajadoras sociales de base? Lo único que tendrían que haber hecho es acabar de desarrollar ese sistema. Lo que han hecho, al final, ha sido todo lo contrario. [...] Que ya tiene una trabajadora social de referencia, a lo mejor, que sea esa persona la que le haga el acompañamiento en todo el procedimiento, ¿no? Y que haya una resolución. Te hacen un informe y te dan un recurso. Eso se hubiera hecho en mucho menos tiempo. A la gente le cuesta entender eso de pasar de un procedimiento a otro, de la Junta, al Ayuntamiento. (Trabajadora Social OAD, E10)

En cambio, otras personas entrevistadas que ocupan puestos de alto nivel en la gestión de la LAPAD en la Junta de Andalucía, afirman que para la implantación del SADA se han basado en las redes y estructuras existentes creadas por los servicios sociales comunitarios, que desde los años ochenta tenían un considerable desarrollo y mantenían una gran implicación en la vida local, en el barrio o el distrito, en la mancomunidad. Por ello, con la intención de reforzar y homogenizar el sistema de provisión de cuidado, señalan las mismas fuentes, se ha destinado una importante partida presupuestaria para la aplicación de la Ley:

Para que eso se lleve a cabo [la aplicación de la LAPAD],financiamos a las corporaciones locales con un programa específico que se llama Refuerzo de los Servicios Sociales Comunitarios para la Atención a la Dependencia, en el que se invierten más de diez millones de euros al año. (Gerencia de la ASSD, E4)

Se pretendió poner en marcha, pues, un gran engranaje administrativo para gestionar estos procedimientos individuales de solicitud de atención, de clasificación, así como los ritmos de respuesta adecuados por parte de los entes públicos. La organización de un sistema global de atención a las necesidades de cuidado de la población andaluza, perseguía simplificar la gestión burocrática con respecto a la anterior proliferación de diferentes 
conciertos con diversas entidades y empresas privadas. No obstante, apenas hubo tiempo de poner en marcha la ASSD, una estructura pensada y enmarcada en el conjunto de los recursos y categorías que originalmente se contemplaban en la Ley, ya que debido a las políticas de austeridad desde fines del 2012, y hasta bien entrado 2014, tan sólo se han resuelto expedientes de extrema urgencia, es decir, los de aquellas personas que viven en situaciones insostenibles, tal como se afirma desde diferentes perspectivas (Gerencia de la ASSD, E4):

Básicamente, desde finales de 2012 hasta mediados de 2014 se han resuelto, únicamente, expedientes que se llaman de urgencia, es decir, situaciones ya completamente extremas. (Trabajadora Social OAD, E10)

\subsubsection{Una competencia (ineludible) de lo público}

En cualquier caso, el sistema se ha ido implantando y generando fórmulas en las que están implicados de diferentes modos y, en ocasiones, con condiciones laborales y salariales diferentes, profesionales contratados por las administraciones locales, autonómica y organismos creados ad hoc para la aplicación de la LAPAD. Tal como sostienen las personas implicadas en dicho proceso y que han colaborado en esta investigación, también ha sido complicado para los profesionales de las diversas administraciones y empresas privadas conocer y entender el procedimiento para relacionarse con las diferentes instituciones y gestores implicados en su aplicación. Y, aunque, por un lado se reconoce el problema que genera a las personas usuarias, y también a los trabajadores implicados, el identificar y conocer cómo operan estos nuevos mecanismos burocráticos, por otro lado, se argumenta que era necesaria cierta supervisión y unificación de procedimientos en la administración tanto en los procesos de valoración, como en el seguimiento, la inspección y evaluación, "porque tiene que ser una competencia indelegable de lo público" (gerencia de la ASSD, E4). Además, la Ley presenta no pocos retos para dar forma al derecho subjetivo que se contempla y se publicita como uno de los aportes más avanzados de dicha legislación:

Los servicios sociales siempre, en este país, [han contado con] un modelo de atención no basado en derechos subjetivos, sino en políticas relacionadas con prestación de servicios, pero sin generar un derecho subjetivo de ciudadanía. El cuarto pilar del bienestar social, que son los servicios sociales, nunca han sido reconocidos como derecho subjetivo. (Gerencia de la ASSD, E4)

Por tanto, la LAPAD plantea el reto de respetar este derecho subjetivo a la par que los políticos se afanan por encontrar criterios y fórmulas homogeneizadoras y democráticas más allá de las necesidades concretas culturalmente arraigadas y corporalmente situadas de cada persona. El derecho subjetivo (lo concreto) se subsume así en las prestaciones democratizadas (lo abstracto), y se convierte en un servicio de cuidado estandarizado, donde la particularidad, la opinión o el gusto personal de quien tiene la necesidad quedan en segundo plano. En la gramática del cuidado, del buen cuidado, de la que habla Jean Tronto (1993), por la que se resuelve el sistema de prestación de cuidado en Andalucía, gana lo universal, como generalidad abstracta, en su fundamentación y pierde la responsividad, como atención a lo particular y como la capacidad de la persona que recibe el cuidado de dar una respuesta, una valoración con consecuencias de la forma de cuidado que recibe (Tronto, 1993; Muñoz Terrón, 2010). Otros trabajos (Pattaroni, 2005) abordan también precisamente esta tensión entre los requerimientos para dar respuesta a las necesidades, que se enmarcaría en lo personal, subjetivo y carnal, y su relación con las instituciones, que tienden a homogenizar la prestación de cuidado. Lo que bien podría salvarse buscando nuevos criterios que dialoguen con «el otro concreto», tal como plantea Seyla Benhabib, es decir, partir de considerar a cada uno de los seres humanos como un individuo situado, encarnado, contextualizado, con una historia, una constitución afectivo-emocional concreta, con sus intereses y sus afectos (Benhabib, 1992: 42-49). Tomando en cuenta las puertas que abría la Ley, al considerar el derecho al cuidado como un derecho subjetivo, bien podría haberse introducido este criterio en lugar de priorizar otros más técnicos y homogeneizadores, como los baremos para clasificar a las personas en función de determinados ítems y colocarles (o no) la etiqueta de "dependiente", u otros procesos similares de resemantización y reclasificación de las personas. Algún tipo de equilibrio entre justicia y cuidado; universalidad y contexto; principios universales y prácticas locales, habría de ser posible para conseguir mejores definiciones de lo bueno y lo justo, en las que tengan lugar la dependencia y la vulnerabilidad, sin perder el universalismo como horizonte normativo (Nussbaum, 2007).

De algún modo, también para racionalizar el sistema se pierde lo local y lo comunitario aun a riesgo de burocratizar el proceso. Por tanto, los sistemas de clasificación parecen jugar un papel mucho más importante que el principio de reconocimiento del derecho subjetivo: las baremaciones y los test para clasificar las actividades de la vida diaria que la persona baremada puede realizar por sí misma, sin ayuda, o bien a qué nivel de dependencia se ha llegado. Estos baremos, que la crisis económica ha demostrado que pueden llegar a tener una gran variabilidad, lo que deja claramente visible su artificio, y las clasificaciones efectuadas a partir de ellos, permiten que la persona, en función de la etiqueta que reciba, pueda acceder o no a determinados servicios de los que contempla la Ley. Sin embargo, otros aspectos que antes eran considerados por las trabajadoras sociales de su entorno más inmediato, que se basaban en aspectos más holísticos y cualitativos de la vida de la persona, como las interacciones con su red familiar y de amistad o su forma de entender la vida, son ahora obviados muy a 
menudo. Y ello hace que la persona que es también ese cuerpo baremado, experimente una merma en su identidad y en su capacidad de agencia (Cerri, 2015).

No obstante, la pretensión de la ASSD en Andalucía es agilizar todo el procedimiento para la provisión de servicios en función de la aplicación de ciertos baremos estandarizados y la contratación de servicios, respetando el derecho subjetivo.

Los servicios sociales siempre, en este país, [han contado con] un modelo de atención no basado en derechos subjetivos, sino en políticas relacionadas con prestación de servicios, pero sin generar un derecho subjetivo de ciudadanía. El cuarto pilar del bienestar social, que son los servicios sociales, nunca han sido reconocidos como derecho subjetivo. (Gerencia de la ASSD, E4)

Pese a la importante inversión que por parte de la Junta de Andalucía se pueda haber realizado en crear servicios públicos directamente gestionados por esta administración, ha sido necesario recurrir a los conciertos, en tanto que, con los servicios públicos con que contaba la administración autonómica andaluza, era imposible poner en marcha el nuevo sistema de provisión de cuidado a implantar con el desarrollo de la LAPAD.

[I]mposible poner en marcha el sistema de dependencia sin contar con la iniciativa privada y la concertación. (Gerencia de la ASSD, E4)

En otro aspecto más, la aplicación de la Ley no parte de cero en este sentido, puesto que ya existía un sistema de concertación ampliamente desarrollado, si bien su volumen no era tan fuerte como el que se genera con la implantación de dicha ley.

Pero más allá de su dimensión cuantitativa, cabe preguntarse si realmente tiene ventajas para la organización de los servicios esta externalización, como ha ocurrido, por ejemplo, con la gestión de la ayuda a domicilio. Esta es competencia de las corporaciones locales y, sin embargo, ello no se ha traducido en el mantenimiento de un servicio que, según los profesionales entrevistados, funcionaba razonablemente bien dentro de los márgenes institucionales, y que con su externalización por la vía de la subcontratación pública probablemente ha ganado tanto en flexibilidad, como también lo ha hecho en precariedad.

Pero, ¿por qué un servicio como la teleasistencia no se ha externalizado en Andalucía? Según los responsables de gestión de la Agencia y de dicho servicio, porque es económicamente eficiente (gerencia de la teleasistencia, E6), siendo eficaz y con una cobertura universal (gerencia de la ASSD, E4). Entonces, si ha sido posible mantener un sistema de atención universal, de calidad, muy bien valorado por los “usuarios” y eficiente en términos económicos, que se ha convertido en un referente en Europa, ¿por qué no se ha aplicado este mismo modelo de la teleasistencia en relación con el servicio de ayuda a domicilio? Como señalan en la empresa adjudicataria de un concurso para la prestación del servicio de ayuda a domicilio en varios municipios de Andalucía, este modelo externalizado permite ofrecer una atención flexible para adaptar jornadas y ritmos, horarios preferidos por los que demandan este recurso y, además, abaratar costes. Esta flexibilidad es considerada como muy positiva tanto en relación con las personas que reciben dichas prestaciones, como en relación con la propia administración, no así para las condiciones laborales de los profesionales que desempeñan este trabajo.

Las responsables del ayuntamiento directamente están en la realidad y son conscientes de los problemas de la gestión de ayuda a domicilio... Usuarios que, en general, se quejan, porque todo el mundo quiere recibir la ayuda, por ejemplo, a las diez de la mañana, personas que no quieren que el cuidador sea inmigrante, que se quejan porque no les ha limpiado la casa. [...] Este último problema es muy grande, no se entiende bien el servicio de ayuda a domicilio. (Coordinadora Empresa Servicio de Ayuda a Domicilio, E9)

Sin embargo, entre la administración autonómica y la local existen tensiones en relación con este servicio de Ayuda a Domicilio. De hecho, desde esta última perspectiva se señala a la Junta de Andalucía como responsable del paulatino desmantelamiento del servicio municipal de ayuda a domicilio existente antes de que se implantara la LAPAD, que era prestado directamente por los ayuntamientos sin tener que mediar ningún tipo de concierto, en concreto se denuncia la precarización laboral que conlleva la subcontratación de este servicio, mientras que hay empresas que obtienen beneficio de ello.

Todavía quedaban ayuntamientos, antes de la Ley, donde las trabajadoras eran personal del Ayuntamiento, eran trabajadoras con sus derechos. Empezó el tema de la Ley de Dependencia y de la precarización, de subcontratar todo el tiempo; no salía más barato, pero alguien se llevaba una parte, que eran estas empresas. Entonces, los Ayuntamientos se quejaban de que había empresas que le hacían ofertas de precio hora más barato. (Trabajadora Social OAD, E10).

\subsection{Impacto de las políticas de austeridad en el sistema de provisión de cuidado}

Los recortes, fruto de una serie de decisiones políticas para hacer frente a la crisis, conllevan numerosos obstáculos en la aplicación efectiva de la Ley a juicio de todos los entrevistados. Se apunta que éste ha sido el principal problema afrontado en esta región para su implementación:

Andalucía ha estado durante dieciocho meses, desde mayo del 2012 hasta noviembre del 2013, 
en una situación de stand by... Desde el año 2012, de financiar un $50 \%$ el Estado, $150 \%$ [las] comunidades autónomas, venimos financiando cada vez un mayor porcentaje. Y, en este año 2014, estamos en una financiación del $78 \%$ por parte de la comunidad autónoma, frente al $22 \%$ por parte del Gobierno de España. Eso, evidentemente, supone un quebranto en las arcas, y ésa es nuestra principal dificultad gestora, porque los servicios se siguen manteniendo. (Gerencia de la ASSD, E4).

En última instancia, se acusa al Gobierno de España, y especialmente al Decreto $20 / 2012^{8}$, de ser responsable de buena parte de los males que aquejan a la implantación de la LAPAD en Andalucía, pues tanto el contenido normativo, que obliga a establecer restricciones en la frecuencia, simultaneidad e intensidad en ciertas prestaciones, como las reducciones presupuestarias en sí, llevan a la aplicación de la Ley en esta región a una encrucijada de la que, según afirman, sólo la voluntad política la puede sacar. Así, las comunidades autónomas se encuentran enormemente condicionadas por dichas restricciones presupuestarias y encorsetadas por los nuevos decretos que se dictan para desarrollar las políticas de austeridad en el sector, y por tanto, cuentan con un margen que se ha estrechado demasiado, como para poder mantener un modelo autonómico propio de gestión del sistema de provisión de cuidado. De hecho, en la ASSD se considera estar realizando un sobreesfuerzo presupuestario que no se sabe cuánto tiempo se podrá mantener, tal como se apunta en el verbatim citado supra. Se da cuenta así de la existencia de numerosas tensiones entre el gobierno autonómico y el gobierno central para poder aplicar el tipo de organización social del cuidado que pretenden. Del mismo modo, aflora la existencia de diferentes culturas y formas organizativas locales que llevan a poner en cuestión la posibilidad de hablar de un régimen de cuidado andaluz, en tanto que las diferencias entre unos rincones y otros de Andalucía son considerables. Lo que nos conduce a hablar de la inexistencia de un modelo para toda la región, por mucho empeño que se haya puesto en ello con la creación de la ASSD. Además, los esfuerzos realizados para homogenizar el sistema lo han hecho a costa de minar el derecho subjetivo y, en cierto modo, debido a los mecanismos que instauró, las estructuras y formas de trabajo social locales en relación con la provisión de cuidado que ya existían y que no funcionaban mal antes de que se implantara la LAPAD, si bien su perspectiva de partida era asistencial y no universal. Las expectativas que inicialmente suscitó el saber que cuantiosos recursos serían dedicados a estas cuestiones en Andalucía, se fueron diluyendo a medida que la crisis iba impactando sobre los diversos mecanismos de su ensamblaje, dejando una estela de limitaciones y de precarización tras de sí.

\footnotetext{
${ }^{8}$ Real Decreto-Ley 20/2012, de 13 de julio, de medidas para garantizar la estabilidad presupuestaria y de fomento de la competitividad.
}

El contexto de crisis, además, ha condicionado todo el proceso de su puesta en marcha, ya que no ha permitido dotar a dicha agencia de recursos económicos suficientes para poder "convencer" a las agrupaciones locales y los diversos ayuntamientos de su extenso territorio. Las disputas y las negociaciones sobre cómo se entiende el cuidado, así como la forma misma de atender a quienes más lo necesitan han tenido lugar en un contexto de miedo y contención, para no perder lo que ya se había consolidado.

\subsubsection{Profesionalización del trabajo de cuidado: ¿una asignatura pendiente?}

Desde el punto de vista de la creación de empleo, la Ley ha generado puestos de trabajo por la necesidad de una mayor contratación de profesionales "cualificados" para gestionar los servicios y las demandas que ha habido, tanto en las propias administraciones, como a través de las empresas y organizaciones implicadas en el sistema de cuidado andaluz. Como señala un gestor de la ASSD, se trata de un sector muy dinámico:

Por cada millón que se invierte en servicios sociales en general, y en particular en el tema de la dependencia, se generan más de 27 empleos directos y no deslocalizables, que ningún sector productivo de este país es capaz de generarlo, ni incluso la construcción en sus mejores tiempos. Se han creado muchísimos puestos de trabajo al amparo de la Ley, en Andalucía, tenemos más de 45.000 personas trabajando. (Gerencia de la ASSD, E4)

No obstante, al analizar la implantación de la LAPAD en Andalucía en estos últimos años, todos los entrevistados la relacionan directamente con los ajustes. Por ejemplo, una delegada sindical de CC.00. destaca cómo a partir de 2012 se produce una reducción presupuestaria bastante considerable que se plasma en: menos trabajadores, menos horas, menos meses. En ello coinciden tanto trabajadores de Unidades de Estancias Diurnas como de Residencias: no se cubren bajas, no se reconocen trienios, se congelan salarios, e incluso para poder mantener abiertos algunos centros concertados han tenido que adaptarse prestando nuevos servicios, por ejemplo, incrementando jornadas laborales, intensificando el trabajo, o asumiendo, sin ampliar los equipos, nuevas responsabilidades y competencias que permitan fidelizar a los otros "usuarios", que empiezan a ser vistos ahora como "clientes" Sirva como ejemplo, aparentemente anecdótico, de ello, el del Director de Centro de Día privado (E14) que acostumbra a visitar a sus "usuarios" cuando están ingresados en el hospital. Hasta fines de 2012, la prórroga de los trabajadores contratados para la gestión de la atención a las personas con necesidades de cuidado en su vida cotidiana en las administraciones públicas andaluzas se hacía automáticamente cada 31 de 
diciembre, duraba doce meses y eran las mismas personas las que integraban los equipos, lo que daba continuidad al servicio en el plano interno y también en la coordinación con otras instituciones y empresas implicadas en el sistema de provisión de cuidado en Andalucía, en "la dependencia”. Ahora no es así.

A día de hoy [diciembre 2014], en el Ayuntamiento de X [capital de provincia de Andalucía] no hay trabajadores de refuerzo de la dependencia, lo hacen las compañeras de plantilla de los centros de servicios sociales. (Delegada Sindical, E13).

Hasta que se produce una nueva contratación pasan meses sin cubrirse las bajas laborales o sin que se incorporen nuevos profesionales. Al no existir un procedimiento de sustitución automática se recurre a las bolsas de trabajo tanto para trabajadores sociales como para otro personal implicado en la gestión de la Ley, cuando hay que cubrir algún puesto. Ello significa que los profesionales externos a la administración, así como los denominados "usuarios", pierden los referentes, sus contactos para hacer las gestiones, para coordinar tanto los casos "atascados" por el parón en la aplicación de la Ley como los más "urgentes". Muchos admiten encontrarse perdidos, porque ni siquiera los números de teléfono con los que se comunicaban con los gestores locales están ahora operativos; ello les obliga a hacer numerosas llamadas hasta dar con el/ la profesional que lleva el caso en cuestión, o bien acercarse en persona a las delegaciones provinciales para ver con quién y cómo coordinarse, cuando durante años contaban con interlocutores con los que mantenían un trato cercano, estaban al tanto de la evolución de los expedientes y tenían el mecanismo de coordinación más engrasado (Trabajadora Social Residencia Privada, E7).

Las condiciones de trabajo de los cuidadores privados constituyen una cuestión importante que no ha resuelto la LAPAD. Generalmente, cuando el trabajo de cuidado se realiza de forma privada se sigue llevando a cabo en un contexto de precariedad, pocas veces se ofrece contrato. En los hogares, por ejemplo, en numerosas ocasiones no se reconocen los derechos de los trabajadores como sería deseable. Se prometen contratos que nunca llegan y el salario es bajo, cuando además del cuidado se exige la realización de otras tareas como la limpieza doméstica (como se denuncia en las entrevistas: Oficina Desarrollo Social, E1; Asociación Empleadas Hogar, E5; y, Trabajadora Social OAD, E10). Lo mismo ocurre en las agencias de colocación, empresas intermediarias entre la familia y el cuidador, que a menudo no respetan la Ley de Empleadas de Hogar de $2011^{\circ}$, cuando están en la obligación de hacerlo. En estos casos, a las duras exigencias laborales se añade además el estrés de ir de un domicilio a otro, con apenas tiempo para los desplazamientos, o

9 Ley 27/2011, de 1 de agosto, sobre actualización, adecuación y modernización del sistema de Seguridad Social (Integración del Régimen Especial de Empleados de Hogar en el Régimen General). trabajar más horas de las que se contemplan en los contratos en función de las necesidades que sobre la marcha van surgiendo en la familia empleadora (Asociación Empleadas Hogar, E5).

La existencia de legislación ha supuesto que se visibilice la necesidad de tener presente las leyes que apoyan a las trabajadoras de cuidado y se conciencien poco a poco de sus derechos, como pretende la Asociación Sevillana de Empleadas de Hogar creada en 2012 (Oficina Desarrollo Social, E1). Para los cuidadores privados el ser contratados por una empresa solvente de servicio de cuidado, como la que gestiona el servicio de ayuda a domicilio en Sevilla, supone una mejor opción que el trabajo realizado en hogares, porque reconoce sus derechos en cuanto a salario, vacaciones, cotizaciones a la Seguridad Social o al sistema de pensiones. Estas empresas tienen que regirse por convenios provinciales de colaboración para la gestión de la ayuda a domicilio que exige un reconocimiento de derechos laborales.

A mayor antigüedad, el precio de la hora mejora (10/hora); por un trabajo de 33 horas a la semana, se puede cobrar 900 euros, que es lo mismo que se puede cobrar como trabajadora interna, sin reconocimiento en algunos casos de sus derechos. (Asociación Empleadas Hogar, E5)

Sin embargo, para quienes trabajan cuidando sin un contrato indefinido, como ocurre en las empresas de colocación, el trabajo de ir de casa en casa tiene una repercusión negativa sobre los usuarios, que se quejan de que les cambien de persona que cuida cada cierto tiempo, porque a la anterior se le ha acabado el contrato. [...] Para las personas que atienden todos los días las demandas de la dependencia, la contratación de cuidadores por las empresas ha supuesto también una rebaja en la cuantía de la retribución por hora trabajada en la ayuda a domicilio; todavía quedaban ayuntamientos antes de la ley donde las trabajadoras eran personal del Ayuntamiento, eran trabajadoras con sus derechos. Empezó el tema de la Ley de Dependencia y de la precarización, de subcontratar todo el tiempo; no salía más barato, pero alguien se llevaba una parte, que eran estas empresas. Entonces, los Ayuntamientos se quejaban de que había empresas que le hacían ofertas de precio hora más barato. (Trabajadora Social OAD, E10)

También la LAPAD ha supuesto mejora en la formación de las personas que trabajan en el sector del cuidado ante la necesidad de profesionalizar el servicio, algo que era igualmente reclamado por los cuidadores remunerados: los trabajadores públicos contratados por el servicio de teleasistencia, que tienen que realizar unas horas determinadas de formación; o los trabajadores de las empresas que gestionan el servicio de ayuda a domicilio, que tienen reguladas unas horas de formación. Se han ido generando recursos nuevos también, al igual que en 
su momento se hizo el mapa de recursos sanitarios, ahora se está trabajando para que con la nueva Ley de Servicios Sociales que está en proceso de tramitación, se genere un mapa de servicios sociales que permita en un futuro, organizar mejor el sistema de atención a la dependencia a nivel local.

Un mapa que va a responder a tres objetivos: va a dar respuesta a una guía de recursos, para que cualquier ciudadano de Andalucía pueda entrar y saber qué recursos hay en cualquier municipio; un objetivo de planificación, que te permita redistribuir el conjunto de los recursos y de los servicios en el territorio andaluz de manera homogénea; $y$ el tercer objetivo, que sirva para la gestión, es decir, para que los profesionales que trabajan en materia de servicios sociales puedan gestionar mejor los propios recursos. (Gerencia de la ASSD, E4)

\subsubsection{Efectos sobre las prestaciones recibidas}

La ayuda a domicilio ha visto reducido tanto el número de horas como la intensidad de la ayuda, con la aplicación de los decretos de fines de $2013^{10}$, lo que es claramente insuficiente para personas que tienen grandes necesidades de atención en su vida cotidiana, clasificadas como con "gran dependencia" o "dependencia severa". Por tanto, las condiciones en las que se cuida han empeorado tanto para el o la trabajador/a que presta dicho cuidado, como para la persona que lo recibe o que lo demanda, así como para los cuidadores familiares que actúan como una red de salvación cuando lo público no llega.

La ayuda a domicilio, con lo que han bajado las horas, se queda prácticamente en una hora y media al día. Antes, era 90 horas al mes; ahora, se ha reducido a 40-70 horas al mes. Eso no es nada para pacientes con mucha supervisión -con párkinson, con alzhéimer, con deterioro cognitivo-, eso no es nada, una hora. (Trabajadora Social CS, E11)

Los recortes también han afectado a quienes viven en centros residenciales, en dos sentidos. Por un lado, las plazas concertadas que causan baja no se han cubierto entre 2012 y 2014, a la par que los conciertos con la Junta de Andalucía obligaban a mantenerlas disponibles, por lo que algunas residencias han llegado a cerrar por insolvencia. Ello ha obligado, por un lado, a trasladar a personas mayores residentes desde el centro donde vivían a otro, con los problemas de adaptación que conllevan

${ }^{10} \mathrm{El} 27$ de diciembre de 2013, se aprueban dos decretos relacionados con la atención a la dependencia: el Real Decreto 1050/2013, de 27 de diciembre, por el que se regula el nivel mínimo de protección establecido en la Ley 39/2006, de 14 de diciembre, de Promoción de la Autonomía Personal y Atención a las personas en situación de dependencia; y el Real Decreto 1051/2013, de 27 de diciembre, por el que se regulan las prestaciones del Sistema para la Autonomía y Atención a la Dependencia, establecidas en la Ley 39/2006, de 14 de diciembre, de Promoción de la Autonomía Personal y Atención a las personas en situación de dependencia. este tipo de cambios; por otro lado, los tiempos de espera han sido muy largos para las personas que necesitaban una plaza, y cuando finalmente han logrado acceder a una, en el mejor de los casos su estado general, así como el de sus cuidadores, se había deteriorado bastante, en el peor, la persona había fallecido. De hecho, se da la paradoja de que las plazas residenciales que se han ocupado en estos dos últimos años (2013-2014) son para dar respuesta a situaciones extremas, cuando la persona mayor se encontraba en un estado que se calificaba como de urgencia social o médica (por ejemplo, enfermos de alzhéimer muy avanzado), y las que se está dando salida desde que han empezado a revisarse los casos "atascados", son también personas a las que se ha asignado un alto grado de dependencia. Por tanto, los centros residenciales están cambiando su fisonomía, atendiendo cada vez más a una población necesitada de más y más cuidados, más dependiente de estas atenciones, pero con los mismos, e incluso menos, recursos, y se está incrementando la edad media de las personas ingresadas así como el nivel de necesidades de atención que presentan. Las consecuencias últimas que estos procesos puedan tener para la calidad del cuidado que reciben estos mayores están por analizar.

En los centros residenciales, los problemas derivan, en parte, de que no se ocupa la totalidad de plazas concertadas, pero también de que las bajas en las plazas de residentes ya no se producen por decesos o por traslados a otros centros, sino porque los familiares están sacando a sus mayores de las residencias y llevándolos a sus hogares:

Antes, las plazas que teníamos concertadas con la Junta no podíamos ocuparlas con plazas privadas; a partir de ahora, como no nos pagan la reserva, pues podemos utilizarlas. Yo, por ejemplo, tengo veinte en concierto, pues yo ahora mismo la Junta me tiene ocupadas dieciocho, pues las dos restantes de la Junta las tengo yo ocupadas con plazas privadas mías. Eso antes no podía ser. Lo que pasa [es] que lo tienes que comunicar. 0 sea, que recortes, hay, porque antes siempre te cubrían el cien por cien; ahora, no. [...] La gente normalmente sale del sistema, porque se muere, vamos. Entonces, hay ciertos recortes [...] Dos plazas menos son 3.000 euros al mes, que al año son 36.000040 .000 , con lo cual son recortes. Y esto en una residencia chica; tú imagínate a nivel de la comunidad autónoma andaluza, pues son millones y millones de euros. (Directora Residencia Pública, E12)

El desempleo ha dado lugar a que muchas familias saquen a sus mayores de las residencias. Imagínate una persona que tiene una pensión de 500 euros; quita los gastos de casa (teléfono, luz, agua, etc.), y de lo que le queda tienen que pagar un $40 \%-y$ no es caro-. Muchas familias no quieren que vayan, porque no tienen posibilidades de ir, no les llega. (Trabajadora Social CS, E11) 
Si, como se ha apuntado más arriba, con el Decreto de 20/2012 se restringe la calidad de la atención a las necesidades de cuidado en muchos sentidos, los decretos de diciembre de 2013 la limitan aún más. Así, se suprime la compatibilidad entre los distintos servicios, modelo que era clave en el SADA, que permitía a los mayores residir en sus hogares o con sus familiares con el apoyo de diversos servicios que, operando simultáneamente, descargaban a las familias, a la par que proporcionaban una adecuada atención al mayor, por ejemplo, mediante la combinación de la teleasistencia, la ayuda a domicilio y el centro de día.

Antes de esta fecha, se financiaba por parte del Gobierno de España el $50 \%$ de cada uno de los servicios que tenía el servicio o prestación; [eso] quiere decir que el Gobierno de España ya no paga compatibilidad por los servicios. Si tú quieres tener servicios que sean compatibles y dar más de un servicio o más de una prestación, lo paga la comunidad autónoma, el servicio de teleasistencia, en Andalucía, lo pagamos a pulmón, porque ésa no se considera una prestación principal, es el único servicio de gestión pública directa de Europa, y somos un referente. (Gerencia de la ASSD, E4)

La sociedad andaluza se caracteriza por un fuerte arraigo de la cultura familista, hecho del que se hacen eco las estrategias políticas de las distintas administraciones. En Andalucía se da incluso un modelo familista extremo, basado en la provisión directa de una parte muy importante de los cuidados por parte de las familias, es decir, sustentado por las mujeres fundamentalmente a través de la solidaridad intergeneracional (Martín Palomo, 2010a; 2013). Pero se da la paradoja de que se puede estar reforzando dicho familismo debido a cómo se ha gestionado la atención a las situaciones de dependencia en un contexto de crisis, en tanto que los recortes en los recursos para los centros residenciales, inciden en la calidad del trabajo efectivamente prestado, a la par que los problemas económicos de las familias más afectadas por el desempleo de sus miembros y por la crisis económica pudieran estar llevando, tal como afirma uno de los entrevistados (Director de Residencia Privada, E15), a algunas familias a sacar a sus mayores de las residencias como una decisión que les permita salir adelante económicamente, aunque ello suponga una sobrecarga para muchas mujeres, así como perdida de cierta calidad en la atención recibida, ya que el peso de la decisión no recae en la voluntad o la capacidad de cuidar mejor de la persona que lo necesita, sino que actuarían empujados por la precariedad del conjunto de la economía familiar.

\subsection{Un derecho, en vías de tornarse universal, en juego}

La dificultad para atender adecuadamente a las necesidades de toda la población que tenga necesidades de cuidado en su vida cotidiana para las que precise ayuda de otras personas con mayor o menor intensidad y continuidad, es un problema reconocido. Para poder darles respuesta se requieren recursos económicos suficientes e implicar a diversas administraciones y actores sociales. La LAPAD ha supuesto, sin duda, una inversión importante para la atención a las personas consideradas dependientes, ahí parecen coincidir todos los entrevistados. Pero, ¿se ha gestionado adecuadamente?, ¿es suficiente?

\subsection{1. ¿Hubo despilfarro?}

En varias entrevistas mantenidas con los gestores privados se afirma que se produjo cierto exceso a la hora de conceder servicios o prestaciones a personas que, vistas con criterios de hoy, cuando los recursos son mucho más escasos que entonces, no lo necesitarían tanto (Gerencia de la ASSD, E4; Trabajadora Social OAD, E10; Director Centro de Día Privado, E14). Aquella supuesta "alegría” a la hora de conceder ayudas económicas, servicios o plazas de residencia pública o concertada ("como si fuera un hotelito", en palabras del Director de Residencia Privada, E15), sería la que ahora fuerza a replantear el modelo.

\section{Al principio, se ofrecieron los servicios de manera indiscriminada, en cierta parte; se les dio servicio a personas que, por sus características, a lo mejor no tenían que tener tanto tiempo de servicio. (Coordinadora Empresa Servicio Ayuda a Domicilio, E9)}

Un (presunto) “despilfarro” que en buena medida habría originado aquel modo de gestión no sea sostenible actualmente (v. gr. Director Residencia Privada, E15); cuando, con criterios más austeros, de eficiencia económica, se exige ajustar presupuestos y prestaciones. Haber hecho un uso inadecuado de los siempre limitados recursos públicos pudiera tener como consecuencia, ahora, que el sistema que se pretendía universal ya no sea sostenible y que se tenga que dar prioridad a lo más urgente, esto es, que el conjunto de la atención se asistencialice. De este modo, se atendería sólo a las personas cuya situación es clasificada como más dependiente, es decir, los más mayores de entre los mayores, 0 aquellas personas que se encuentran en peor estado de salud, o quienes tienen más reducidas sus capacidades. Así pues, aunque se alberguen esperanzas de que se amplíe la cobertura, no parece probable que se incorporen al sistema próximamente otros grupos de "dependientes", es decir aquellos casos etiquetados con un grupo o nivel de dependencia menor que el que recibe atención en la actualidad. Tampoco parece prioritario en este contexto, una vez reactivado el mecanismo que estaba paralizado, atender a las personas a las que se han asignado grados de dependencia menos avanzados. Antes bien, los conceptos, así como los grados de dependencia con que se regulan los diferentes servicios o recursos a los que la adscripción a uno u otro grado dan 
derecho, parecen haberse endurecido bastante en los últimos tiempos, es decir, se han vuelto más estrictos y exigentes ${ }^{11}$. Ello significa, pues, no sólo que pierde centralidad la perspectiva universal en la atención a las necesidades de cuidado de las personas andaluzas, sino también que los aspectos preventivos y la pretensión de fomentar o, al menos, apoyar la autonomía de las personas el mayor tiempo posible han quedado guardados en algún rincón. Ahora se pretende, únicamente, dar respuesta a toda la denominada "gran dependencia", se está dando paso, por tanto, a un modelo más paliativo, medicalizado y asistencial, en el que el derecho subjetivo ha quedado diluido ante la urgencia de dar respuesta a determinadas necesidades.

\subsubsection{Catálogo oficial frente a catálogo restringido}

Todos los servicios del catálogo que se desarrolla a partir de la aplicación de la Ley no se ofrecen por igual. Ciertos recursos contemplados en él, como por ejemplo, la figura del asistente para la autonomía personal apenas se concedió en Andalucía (hoy día hay entre diez y trece asistentes personales en toda la comunidad autónoma). Y ello, al parecer, por dos motivos: por un lado, se trata de un servicio muy caro; por otro lado, al ser incompatible con otras prestaciones, como por ejemplo, la asistencia a un centro de día, muchas familias optaron por solicitar otros servicios del catálogo. Se apunta asimismo que este tipo de servicios son muy gravosos: "contratar a una persona que esté las veinticuatro horas al día pendiente de ti es muy caro" (Trabajadora Social OAD, E10).

La revisión del grado de dependencia en un tiempo razonable para que dé lugar al derecho correspondiente, tampoco se está posibilitando, en tanto que, tal como se apuntó más arriba, los expedientes están siendo reactivados tras un par de años de estar parados.

Primero se iban a atender los casos más graves, el grado III, el gran dependiente, después el grado II y después el grado I. El grado I lo han aplazado hasta julio de 2015, y veremos a ver si no lo vuelven a aplazar. Luego, además, tú tienes un sistema que está parado; las personas mayores dan bajones de una semana a la otra, y tienes una señora que ha solicitado una revisión del grado, porque está peor y tardan dos años en revisarla. ¿Qué ayuda real se les está dando a las personas con la Ley de Dependencia? (Trabajadora Social $\mathrm{OAD}, \mathrm{E} 10)$

Hay que tener presente también que uno de los problemas a la hora de alcanzar el objetivo de universalidad es que para acceder a los servicios que

${ }^{11}$ Véase la Orden de 6 de noviembre de 2014 por la que se modifica el modelo de solicitud del procedimiento para el reconocimiento de la situación de dependencia en la Comunidad Autónoma de Andalucía (BOJA, 14 de diciembre). ofrece la LAPAD, hay que estar encuadrado dentro de alguno de los grados que se establecen en ella. Esto no soluciona el problema de las familias con miembros adultos que tienen una discapacidad sobrevenida por accidente de tráfico, por accidentes laborales (Zambrano, 2010), u otras situaciones que en la Ley no se han contemplado. Es decir, sin clasificación no hay derecho.

\subsection{3. ¿Brecha de género en la atención a las necesidades de cuidado?}

La Ley, que pretendía ser universal, al asistencializarse en su aplicación, deja en jaque a las personas que no son etiquetadas como absolutamente dependientes, pero que tienen necesidad de ayuda en su vida cotidiana en diferentes sentidos y que no cuentan con recursos para comprar estos servicios en el mercado. En las entrevistas, se plantea también que no se ha tratado por igual a las personas denominadas dependientes si se toma en cuenta el género. Las mujeres como usuarias o receptoras de los servicios a los que igualmente tienen derecho por ley, estarían siendo discriminadas en estos momentos de reajuste de las prestaciones. Este sería, pues, otro elemento que mina la vocación universal en la LAPAD, como afirma una de las entrevistadas.

Con las personas en situación de dependencia, tengo la sensación de que a los hombres se los cuida más, porque la Ley de Dependencia lo que mide es la capacidad que tú tienes de realizar las actividades de la vida diaria; entonces encuentras que le dan grados de dependencia superiores a hombres no por el hecho de que estén más torpes o tal, sino porque de todas formas ese señor no sabe cocinar, no sabe poner una lavadora, se ha quedado viudo. Es que es así, y luego señoras que están ahí, las pobres, que se mueven menos, pero "yo lo que puedo lo limpio...", ellas dentro de su torpeza, de cómo estén, siempre intentan realizar esas tareas, ¿no? A los hombres, se les da muchas veces un grado superior de dependencia, porque son más dependientes en el hogar, que también es cierto, ¿no? Y al final me da la sensación de que todas estas señoras viudas, pobrecitas que están solas, tienen un déficit de cuidado con respecto a esos hombres. Ésa es una cosa que percibo. Los trabajadores sociales tampoco tienen todos esa visión de género. (Trabajadora Social OAD, E10).

Por tanto, se pone de relieve la arbitrariedad con que pueden terminar operando de hecho estos sistemas de clasificación, pues al no tener presente la situación social concreta y encarnada de las personas, tienden a obviar que las mujeres intentan mantenerse activas y no quieren recurrir al cuidado de otras personas como una forma de seguir "cuidando" de sus familiares y no sobrecargarles (Tobío y Martín Palomo, 2003: Martín Palomo y Muñoz Terrón, 2015). 


\subsubsection{Diferenciaciones por hábitat en el acceso a las prestaciones}

Las peculiaridades de los ámbitos rurales en relación con las culturas de cuidado también son destacadas en las entrevistas. Así, se transmite la preocupación de que en el medio rural pueda estarse dando un proceso por el que más personas estén siendo expulsadas de la cobertura del SADA, sea por la dificultad o limitaciones físicas a la hora de acceder a determinados servicios, sea porque en los medios rurales persiste una más fuerte aún, si cabe, cultura familista y opera una mayor presión social para que los mayores permanezcan residiendo en sus propios hogares o en los de sus hijos, es decir, el modelo de "envejecer en casa".

Porque aquí, en Andalucía, el tema de que los cuidados recaen sobre las mujeres de la familia está mucho más asentado. Y decirle a una señora de un pueblo pequeño, como yo le tengo dicho, "Señora, es que lo que le van a proponer es la residencia”, y, claro, dice ella “¿Cómo voy a meter a mi padre en una residencia?”. Una señora, de hecho, me llegó a decir que se le echaría el pueblo encima. [...] También en el ámbito rural está el problema de los desplazamientos; por eso son importantes las prestaciones económicas a las familias en Andalucía, porque aquí hay mucha tradición de cuidar en casa. (Trabajadora Social $\mathrm{OAD}, \mathrm{E} 10)$

\subsection{5. ¿Como en casa, en ninguna parte? El fiasco de las prestaciones económicas}

La LAPAD prevé, como medida de carácter excepcional, la prestación económica para cuidar de un pariente con el que se reside. En Andalucía, ésta se convirtió en una de las prestaciones más solicitadas y más concedidas. Con ella se otorga a quien cuida habitualmente de un familiar identificado como "dependiente", el derecho a cotizar a la Seguridad Social y para el sistema de pensiones, además de otros beneficios sociales, todo ello con cargo a los presupuestos públicos. Con el ya citado Decreto de julio de 2012, se retira la cotización a la Seguridad Social de estas prestaciones económicas que se ofrecían a las familias, lo que ha generado mucho desconcierto y un impacto negativo en la ciudadanía, que ya empezaba a incorporar este recurso a su modelo familiar de cuidado. Muchas mujeres la han considerado de hecho como una suerte de "salario" por cuidar de un pariente en situación de dependencia, lo que de algún modo contribuía a dignificar su trabajo de cuidadora, al adquirir un reconocimiento formal, por un lado, y al aportar con él un (pequeño) ingreso a la economía familiar, por otro. Es decir, con esta ayuda pública, concedida en principio a la propia persona “dependiente" se lograba, además de garantizar su cuidado, el que más mujeres tuvieran un "empleo”, reforzando las economías familiares de los sectores más pobres. No se va a entrar a discutir aquí la trampa que puede encerrar esta visión del cuidado en relación con la igualdad de género, tan sólo cabe hacer mención al ya clásico debate sobre el salario para el ama de casa y el potencial de desigualdad que una medida de este tipo encierra a la hora de perpetuar roles de género (Del Re, 1995; Dalla Costa, 1972, 2006).

Se han tirado cinco, tres, cuatro años cuidando, y ahora no tienen nada. (Gerencia de la ASSD, E4).

Ha habido mucha frustración, mucho cambio normativo, que de repente tienen este derecho, mañana no, pasado nos lo estamos pensando. Crea una incertidumbre impresionante en las personas, lo que recibimos es mucha ira, mucha frustración, mucha pena, resignación también. (Trabajadora Social OAD, E10).

En Andalucía, además, donde hay una cultura muy arraigada y difundida de cuidar en casa, parece que, según se señala, ha habido un uso inadecuado de dichas prestaciones económicas. La idea de ofertar de manera generalizada algo que la Ley contemplaba como posible excepción, tendría su origen en dos fenómenos: uno, que en Andalucía no existía una cartera de servicios para poder dar respuesta a un considerable volumen de población etiquetada como dependiente; otro, la pretensión de regularizar y asignar cierto valor al trabajo de cuidado, generalmente proporcionado de forma no monetizada por las mujeres en las familias:

Hay que darle un valor y hay que darle un precio, incluso. Yo me imagino mañana al presidente del Gobierno diciendo "el año que viene, el que se jubile no va a tener pensión", el follón que se liaría, ¿no? Pues es un poco lo que ha pasado con las cuidadoras: "oye, que a partir de junio de 2012 no vais a tener pensiones, pues ahora las prestaciones económicas solamente se las vamos a dar a menores de edad o personas que viven en entornos aislados". Desde lo que ha supuesto la LAPAD para las mujeres, ha sido "ofrecerte ser una reina” y no conseguirlo. (Trabajadora Social $\mathrm{OAD}, \mathrm{E} 10)$

Sin embargo, la opción de remunerar a la cuidadora (o cuidador) familiar, aunque se mantiene en el catálogo de prestaciones que se ofrecen, ya no se contempla a la hora de otorgar las prestaciones (Trabajadora Social Dependencia, E2; Trabajadora Social Ayuntamiento, E3). Además, a raíz del Decreto 20/2012 deja de ser posible mantener aseguradas a las personas que reciben una prestación económica por cuidar de un familiar con el que conviven y, por tanto, ni cotizan a la Seguridad Social ni al Sistema de Pensiones.

El dinero no lo están dando desde hace tiempo. Aparece en el PIA; en el papel, muy bonito, todavía hacen referencia a la ayuda económica, pero está anulada, no existe, no se da. Hay muchas familias que están esperando por 
problemas económicos, por el desempleo, las cuidadoras dicen "si yo lo estoy cuidando en vez de que venga una persona de fuera, que me den a mí el dinero", pero ya hace que no lo dan. (Trabajadora Social Centro de Salud, E11)

Tal como se apunta en la ASSD, esta medida no era ni pretendía ser de apoyo a las familias en situación de exclusión o muy vulnerabilizadas por el impacto de la crisis, sino que se trataba de una ayuda para seguir cuidando al mayor considerado como dependiente, en unas condiciones algo más decentes de lo que muchos familiares ya venían haciendo. Pero el contexto de crisis profunda ha acentuado la perversión que ya se venía dando con este tipo de ayudas: entre la pensión del mayor cuidado, la ayuda económica recibida para cuidarlo, así como con el dinero que se ahorran al no llevar al mayor a un centro de día, puede sobrevivir una familia que tiene a varios de sus miembros desempleados. Llegan a darse situaciones, incluso, en las que la persona que solicitó ayuda en su día tiene ya un alto grado de deterioro físico o cognitivo, lo que convierte en muy duro el hacerse cargo de su cuidado día y noche durante todos los días de la semana; en estos casos, se apunta que la situación puede llegar a ser extrema para quienes cuidan de esta persona de forma habitual, además de que se priva a la persona mayor de ciertos estímulos que podrían ser muy positivos para reducir su pérdida de capacidades. En parte por ello, las residencias públicas perciben este tipo de ayuda a las familias como una competencia desigual. Además, señalan que, frente a los rígidos estándares que deben cumplir los centros residenciales o de día para concertar las plazas con la Junta de Andalucía, no se ha previsto en la Ley ningún mecanismo de control para supervisar cómo se está cuidando del mayor que vive sólo en su casa, lo que está dando lugar a ciertas situaciones de abandono, e incluso de maltrato:

Cuando la gente demandaba solamente lo del cuidador, hombre, una persona mayor y demente, solamente cuidada por una persona, o tienes que estar muy preparada o vamos... Es que el cuidador se viene abajo totalmente. $Y$ entonces, ¿se ha evaluado en qué condiciones estaba esa persona mayor? ¿Sí o no? Yo creo que no. (Directora Residencia Pública, E12)

Se afirma que desde mediados de 2014 se están recuperando las prestaciones, pero se está resolviendo sólo lo más urgente y ello en un contexto de endurecimiento de las condiciones de vida de las familias en general, que ven reducidas otras prestaciones complementarias como, por ejemplo, la medicación gratuita que también pasa a gestionarse bajo un modelo de copago.

De momento, hasta que se abra la mano, a principios de año [2014] teníamos, solamente, a menores, que se han empezado alrededor de la primavera, porque el compromiso era resolver todos los expedientes de menores antes de que acabara el año. Luego se abrió a personas que viven en un entorno aislado, es decir, que viven en medio del campo, sin un Ayuntamiento que les pueda prestar un servicio profesional. $Y$ ahora se ha abierto también pues a personas que estén terminales y mayores de 90 años. Ése es el criterio, porque no cabe, económicamente, más personas. [...] La Ley de Dependencia llega hasta donde llega, pero no cubre las necesidades. Lo peor del trabajo lo siguen haciendo las mujeres gratis en su casa, y además a costa de no tener pensión el día de mañana, de no tener ingresos a día de hoy [...] Tenemos un empobrecimiento impresionante de la gente. (Trabajadora Social OAD, E10)

\subsection{6. ¿Copago o repago?}

En relación con el copago, si bien se afirma que con la LAPAD nadie se queda fuera por falta de ingresos, de la cobertura de servicios que prevé en tanto que se pretende universal, en la práctica no queda claro que sea así. No hay nada más desigual - se señalaque tratar de la misma manera a personas que están en desigualdad.

Es cierto que si tú tienes una pensión de $\mathbf{2 . 0 0 0}$ euros y estás en una residencia y tienes que poner el $75 \%$, lo pones, pero igual también tienes que responder a otros gastos familiares, y esto te supone mucho. Sí, se presentan quejas, de eso, de gente que dice "mira, si yo doy el $75 \%$ de mi pensión yo no puedo ingresar, que dejo a mi hija separada con dos niños". (Trabajadora Social $\mathrm{OAD}, \mathrm{E} 10$ )

La supuesta “alegría” con que, según se afirma, se pone en marcha la LAPAD en sus orígenes se torna en "rigor" a partir de finales de 2014. Con el desarrollo legislativo surgido al hilo de la puesta en marcha de políticas de austeridad, se pretende que las personas consideradas "dependientes" contribuyan no sólo con su pensión, sino también con su patrimonio para co-financiar los servicios y atenciones que reciban para dar respuesta a sus necesidades de cuidado. De hecho, en noviembre de 2014 se publica un nuevo modelo de solicitud más complejo, para tener en cuenta, no sólo la pensión de la persona que solicita cuidado, sino también otros ingresos y el patrimonio con el que cuente (cfr. supra, nota 10). En la ASSD se sostiene, sin embargo, que es el Gobierno central el que pretende introducir, además de la pensión, el patrimonio en el cómputo elaborado para el copago ("repago", prefiere decir el entrevistado), y que el porcentaje de dicho copago sea mayor, por ejemplo el $90 \%$ de los ingresos del mayor para co-pagar (o re-pagar) su plaza en la residencia. No obstante, en Andalucía se intenta evitar la puesta en marcha de este nuevo esquema de pago compartido por el usuario, pues se considera que se trata de un servicio al que la persona tiene derecho, en tanto que ya ha pagado sus impuestos a lo largo de toda su vida. En este sentido, el copago, con todos sus 
inconvenientes, se habría implantado en Andalucía de manera diferente al resto del país tal como destaca uno de los entrevistados:

Es una de las comunidades que menor participación económica de las personas usuarias propone en relación al copago. Se llegó a un acuerdo en el Consejo Territorial que vinculaba al conjunto de comunidades autónomas para establecer un nuevo sistema de aportación económica de las personas en el coste de los servicios. Andalucía no lo ha llegado a implementar, porque supone, desde luego, un menoscabo importante para la economía de las personas, se paga menos que en otras comunidades autónomas, pero en Andalucía, por mucho que se subiera el copago, eso supondría pues tener un incremento de en torno a unos 40 o 50 millones de euros al año. De 1.200 millones de euros, 40 o 50 no suponen nada. Ése no es un tema que sea significativo en este momento en Andalucía. (Gerencia de la ASSD, E4)

\section{Conclusiones}

El progresivo aumento de personas mayores de 65 años, con el consiguiente incremento de población necesitada de cuidado, han hecho disparar las alarmas de los países de la Unión Europea que, en pleno debate sobre la reforma de los Estados de bienestar, han visto incorporarse a la agenda pública la cuestión de la organización social del cuidado de una creciente población dependiente. En el caso andaluz, los poderes públicos se han esforzado en promover la aplicación la LAPAD para dotar de recursos públicos, vía transferencias económicas y mediante la prestación de servicios (públicos y concertados), que permitan hacer frente a las necesidades de cuidado de las personas en situación de dependencia.

Este escenario se ve ahora desafiado por los ajustes realizados en el marco de la crisis económica que padece España con especial virulencia, y que sitúan al sistema de provisión de cuidado que empezaba a construirse en una encrucijada en cuanto a sus posibilidades de desarrollo. En el proceso de implantación de esta ley en Andalucía, dos ejes se han puesto en tensión: el que va de lo universal a lo asistencial y el que va del derecho subjetivo a la gestión técnica. Derechos apenas asentados, que el impacto de la crisis está poniendo en cuestión. Parece haber un acuerdo en que se han gestionado de una forma poco eficiente los recursos disponibles, no ha habido un modelo equilibrado a nivel territorial y hay que replantear la aplicación de la Ley para crear un sistema de provisión de cuidado en Andalucía con criterios de más eficacia.

Está pendiente resolver cómo incorporar en una lógica de derechos la complejidad del cuidado, es decir, vinculado a un principio inherente a la igualdad de trato, de oportunidades y de trayectoria. Resulta pues indispensable analizar el cuidado como obligación de la sociedad en su conjunto con sus múltiples implicaciones y derivaciones que trae aparejada. Sólo en la medida en que se lo incluya como un derecho propio y universal (tanto para quienes deben ser cuidados como para quienes cuidan) se logrará un importante avance.

La crisis y los ajustes que se han realizado en su nombre han dejado en suspenso las expresiones de los propósitos más democráticos de la LAPAD, para hacer emerger con más claridad algunos de sus mecanismos de perversión. Entre ellos, poner en cuestión el derecho subjetivo y la vocación de universalidad que incorporaba la Ley, por los que se apostó en su puesta en marcha en Andalucía. Si bien parece se está intentando reconducir esta deriva hacia lo asistencial y lo técnico -lo que, aseguran algunos entrevistados, bien puede deberse a que 2015 es un año electoral-, como "secuela" se avista una nueva definición, más restrictiva y medicalizada de dependencia, más cercana de la cura, en la que el derecho subjetivo queda minado, pues se olvidan además del respeto al derecho subjetivo, aquellos programas centrados en la prevención y en otro pilar fundamental de la Ley, el fomento de la autonomía personal. 
ANDALUCÍA (2014): “Orden de 6 de noviembre de 2014, por la que se modifica el modelo de solicitud del Procedimiento para el Reconocimiento de la Situación de Dependencia en la Comunidad Autónoma de Andalucía", Boletín Oficial de la Junta de Andalucía, no 223, 14-11-14 [<http:// www.juntadeandalucia.es/boja/2014/223/18>, consultado el 30-7-15].

ARTIAGA LEIRAS, A. (2015): "Producción política de los cuidados y de la dependencia: políticas públicas y experiencias de organización social de los cuidados" [tesis doctoral], Universidad Complutense de Madrid [/http://eprints.ucm. es/32816/>, consultado el 30-7-15].

BENHABIB, S. (1992): “Una revisión del debate sobre las mujeres y la teoría moral", Isegoria, $\mathrm{n}$ ㅇ 6 , págs. 37-63.

- (1990) [1986]: "El otro generalizado y el otro concreto: la controversia Kohlberg-Gilligan y la teoría feminista", en BENHABIB, S; y CORNELL, D. (coords.), Teoría feminista y teoría crítica, Valencia, Alfons el Magnánim, págs. 119-149.

BORCHORST, A. (1994): “Welfare State Regimes, Women's Interests and the EC", en SAINSBURY, D. (coord.), Gendering Welfare States, Londres, Sage, págs. 6-44.

CERRI, C. (2015): “Dependencia y autonomía: una aproximación antropológica al cuidado de los mayores", Athenea Digital, nํㅜ 15, vol. 2, págs. 111-140.

DALLA COSTA, M. R. (2006): “La sostenibilidad de la reproducción: de las luchas por la renta a la salvaguardia de la vida", en LABORATORIO FEMINISTA, Transformaciones del trabajo desde una perspectiva feminista. Producción, reproducción, deseo, consumo, Madrid, Tierradenadie Ediciones, págs. 59-78.
- (1972): Las mujeres y la subversión de la comunidad, Madrid, Siglo XXI,

DALY, M. (2004): “Changing conceptions of family and gender relations in European welfare states and the Third Way", en LEWIS, J.; y SURENDER, R. (eds.), Welfare State Change: Towards a Third Way?, Oxford, Oxford University Press, págs. 135-154.

- (2002): "Care as a good for social policy", Journal of Social Policy, nํㅜ 31, vol. 2, págs. 251-270.

DALY, M.; y LEWIS, J. (2000): "The concept of social care and the analysis of contemporary welfare states", British Journal of Sociology, $\mathrm{n}^{0}$ 51, vol. 2, págs. 281-298.

DEL RE, A. (1995): "Tiempo de trabajo asalariado y tiempo del trabajo de reproducción", Política y Sociedad, nํㅜ19, págs. 75-81.

ESPAÑA (2013): “Real Decreto 1050/2013, de 27 de diciembre, por el que se regula el nivel mínimo de protección establecido en la Ley 39/2006, de 14 de diciembre, de Promoción de la Autonomía Personal y Atención a las personas en situación de dependencia", Boletín Oficial del Estado, n우313, 31-12-13, págs. 107.120-107.127 [<https://www.boe.es/boe/ dias/2013/12/31/pdfs/BOE-A-2013-13810.pdf>, consultado el 30-8-15].

- (2013): "Real Decreto 1051/2013, de 27 de diciembre, por el que se regulan las prestaciones del Sistema para la Autonomía y Atención a la Dependencia, establecidas en la Ley 39/2006, de 14 de diciembre, de Promoción de la Autonomía Personal y Atención a las personas en situación de dependencia", Boletín Oficial del Estado, $\mathrm{n}^{0}$ 313, 31-12-13, págs. 107.128107.142 [rhttp://www.boe.es/diario_boe/txt. 
php?id=BOE-A-2013-13811>, consultado el 30-7-15].

- (2012): "Real Decreto-Ley 20/2012, de 13 de julio, de medidas para garantizar la estabilidad presupuestaria y de fomento de la Competitividad", Boletín Oficial del Estado, no $168,14-7-12$, págs. 50.428-50.518 [<http://www.boe.es/diario_boe/txt. php?id=BOE-A-2012-9364), consultado el 30-7-15].

- (2011): "Ley 27/2011, de 1 de agosto, sobre actualización, adecuación y modernización del sistema de Seguridad Social", Boletín Oficial del Estado, no 184, 2-8-11, págs. 87.495-87.544 [<http://www.boe.es/diario_boe/txt. php?id=BOE-A-2011-13242〉, consultado el 30-7-15].

ESPING-ANDERSEN, G. (1990): The Three Worlds of Welfare Capitalism, Cambridge, Polity.

FERNÁNDEZ CORDÓN, J. A.; y TOBíO, C. (2007): Andalucía. Dependencia y solidaridad en las redes familiares, Sevilla, Instituto de Estadística de Andalucía.

KITTAY, E. F. (2002): "When caring is just and justice is caring: Justice and mental retardation", en KITTAY, E. F.; y FEDER, E. K. (eds.), The Subject of Care: Feminist Perspective on Dependency, Lanham, Rowman \& Littlefield Publishers, págs. 257-276.

LANGA, R. et al. (2009): Las cuidadoras y cuidadores de dependientes en el seno de las redes familiares. Una mirada desde la desigualdad, Sevilla, Instituto de Estadística de Andalucía.

LETABLIER, M. T. (2007): “El trabajo de 'cuidados' y su conceptualización en Europa”, en PRIETO, C. (ed.), Trabajo, género y tiempo social, Madrid, Hacer; Madrid, Complutense, págs. 4-84.

LEWIS, J. (1998): Gender, Social Care and Welfare States Restructuring in Europe, Aldershot, Ashgate.

- (1992): "Gender and the development of welfare regimes", Journal of European Social Policy, noำ 2, vol. 3, págs. 159-173.

MARTÍN PALOMO, M. T. (2014): “Los cuidados en las familias. Un estudio a través de tres generaciones de mujeres en Andalucía" [tesis doctoral], Universidad Carlos III de Madrid.

- (2013): “Tres generaciones de mujeres, tres generaciones de cuidados. Apuntes sobre una etnografía moral", Cuadernos de Relaciones Laborales, nํㅜ 31, vol. 1, págs. 115-138.

- (2010a): Los cuidados en las familias. Estudio a partir de tres generaciones de mujeres en Andalucía, Sevilla, Instituto de Estadística de Andalucía.

- (2010b): “Autonomía, dependencia y vulnerabilidad en la construcción de la ciudadanía”, Zerbitzuan, no 48, págs. 57-69 [<http://www.zerbitzuan. net/documentos/zerbitzuan/Autonomia,\%20 dependencia\%2oy\%2ovulnerabilidad.pdf $>$ ].

- (2009): “El care un debate abierto: de las políticas de tiempos al social care", Cuestiones de Género: de la Igualdad y la Diferencia, $\mathrm{n}-4$, págs. 325-355.

- (2008): "Los cuidados y las mujeres en las familias", Política y Sociedad, № 46, vol. 2, págs. 29-49.
MARTÍN PALOMO, M. T.; y MUÑOZ TERRÓN, J. M. (2015): "Interdependencias. Una aproximación al mundo familiar del cuidado", Argumentos. Revista de Crítica Social, no -17 , [<http:// publicaciones.sociales.uba.ar/index.php/ argumentos/article/view/1382>].

- (2013): “¿Cuidar en crisis? Un lugar para la vulnerabilidad en las políticas de cuidados" [comunicación], IV Congreso Internacional en Gobierno, Administración y Políticas Públicas, Madrid, septiembre.

MARTÍNEZ BUJÁN, R. (2014): “Los modelos territoriales de organización social del cuidado a personas mayores en los hogares", Revista Española de Investigaciones Sociológicas, noำ145, págs. 99-126.

MCLAUGHIN, J. (2003): “The ethics of care”, en MCLAUGHLIN. Feminist Social and Political Theory: Contemporary Debates and Dialogues, Londres, Palgrave \& MacMillan, págs. 70-90.

MUÑOZ TERRÓN, J. M. (2010): “Responsividad y cuidado del mundo. Fenomenología y ética del care", Daimon. Revista Internacional de Filosofía, $\mathrm{n}$ 은 49, págs. 35-48.

NUSSBAUM, M. (2007): Las fronteras de la justicia. Consideraciones sobre la exclusión, Barcelona, Paidós.

- (2002): "Amor, cuidados y dignidad", en NUSSBAUM, M. C, Las mujeres y el desarrollo humano, Barcelona, Herder, págs. 321-322.

PATTARONI, L. (2005): “Le care est-il institutionnalisable? Quand la 'politique du care' émousse son éthique”, en PAPERMAN, P.; y LAUGIER, S (eds.), Le souci des autres: éthique et politique du care, París, EHESS, págs. 177-200.

PAUTASSI, L. (2007): El cuidado como cuestión social desde un enfoque de derechos. Santiago de Chile, CEPAL.

RAZAVI, S. (2007): The Political and Social Economy of Care in a Development Context. Conceptual Issues Research Questions and Policy Options, serie Gender and Development Programme Papers, $\mathrm{n}$ ㅇ 3, Ginebra, United Nations Research Institute for Social Development.

SARACENO, C. (2005): “¿Qué derechos y obligaciones, qué tipos de recursos? Visiones de la ciudadanía a través del prisma del género", en VV.AA., Congreso Internacional Sare 2004: ¿hacia qué modelo de ciudadanía?, Vitoria-Gasteiz, Emakunde-Instituto Vasco de la Mujer, págs. 255-278 [<http://www.emakunde.euskadi. eus/contenidos/informacion/pub_jornadas/ es_emakunde/adjuntos/sare2004_es.pdf>, consultado el 30-7-15].

SOJO, A. (2007): “Estado, mercado y familia: el haz del bienestar social como objeto de política”, en ARRIAGADA, I. (coord.), Políticas públicas en América Latina: una historia de desencuentros, Santiago de Chile, CEPAL, págs. 157-170.

TOBío, C. et al. (2010): El cuidado de las personas. Un reto para el siglo XXI, Barcelona, La Caixa, [ [https://obrasocial.lacaixa.es/deployedfiles/ obrasocial/Estaticos/pdf/Estudios_sociales/ vol28_completo_es.pdf〉, consultado 30-8-15].

TOBÍO, C.; MARTÍN PALOMO, M. T.; y FERNÁNDEZ CORDÓN, J. A. (2003): Investigación 
cualitativa como fase previa al diseño del cuestionario, [<http://www.juntadeandalucia. es/institutodeestadisticaycartografia/ redesfamiliares/metodologia/ InvestigacionCualitativa.pdf>, consultado el 30-7-15].

TORNS, T. (2005): "De la imposible conciliación a los permanentes malos arreglos", Cuadernos de Relaciones Laborales, nํ23, vol. 1, págs. 15-33.

TRONTO, J. (2005): “Cuando la ciudadanía se cuida: una paradoja neoliberal del bienestar y la desigualdad", en VV.AA., Congreso Internacional Sare 2004: ¿hacia qué modelo de ciudadanía?, Vitoria-Gasteiz, EmakundeInstituto Vasco de la Mujer, págs. 231-253 [khttp://www.emakunde.euskadi.eus/ contenidos/informacion/pub_jornadas/ es_emakunde/adjuntos/sare2004_es.pdf〉, consultado el 30-7-15].

- (1993): Moral Boundaries. A Political Argument for an Ethic of Care, Nueva York, Routledge, Chapman and Hall.

WILLIAMS, F. y GAVANAS, A. (2008): "The intersection of childcare regimes and migration regimes:
A three-country study", en LUTZ, H. (ed.), Migration and Domestic Work, Aldershot, Ashgate, págs. 13-28.

ZAMBRANO, I. (2010): “La valoración económica del trabajo no remunerado como reconocimiento de los derechos de las mujeres ante el cuidado de la dependencia", Mujer y Economía. Revista Económica de Castilla-La Mancha, n-17, págs. 197-230.

- (2004): “La responsabilidad pública en el cuidado de las personas con discapacidad" [tesis doctoral], Universidad Autónoma de Madrid.

ZAMBRANO, I. et al. (2015): “'Sólo lo más urgente': de lo universal a lo asistencial en el modelo de atención pública a la dependencia en Andalucía”, en VV.AA. Desigualdad y democracia: políticas públicas e innovación social. Actas oficiales del V Congreso de la Red Española de Política Social (REPS). Barcelona, 5-6 febrero 2015, Barcelona, Red Española de Política Social, págs. 1.569-1.589 [<http://repsbarcelona2015.es/actas-delcongreso/>]. 